\title{
Abnormal Presence of the Matrix Extracellular Phosphoglycoprotein-Derived Acidic Serine- and Aspartate-Rich Motif Peptide in Human Hypophosphatemic Dentin
}

\author{
Tchilalo Boukpessi, ${ }^{, \dagger}$ Celine Gaucher, ${ }^{, \dagger \ddagger}$ \\ Thibaut Léger, ${ }^{\S}$ Benjamin Salmon, ${ }^{* \dagger}$

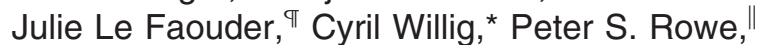 \\ Michèle Garabédian, ${ }^{\ddagger}$ Olivier Meilhac, ${ }^{\S}$ \\ and Catherine Chaussain ${ }^{\star \dagger}$ \\ From the Faculté de Chirurgie Dentaire," University Paris \\ Descartes, EA 2496, Montrouge, France; the Hôpital \\ Bretonneau, ${ }^{\dagger}$ Assistance Publique-Hôpitaux de Paris, Paris, \\ France; INSERM, U561, ${ }^{\ddagger}$ Hôpital St. Vincent de Paul, Paris, \\ France; INSERM, U698, University Paris Diderot and the Centre \\ Hospitalier Universitaire X-Bichat, Paris, France; Institut Claude \\ Bernard, " University Paris Diderot, Paris, France; and The \\ Kidney Institute," University of Kansas Medical Center, Kansas \\ City, Kansas
}

Severe dental troubles are associated with $\mathrm{X}$-linked hypophosphatemic rickets and are mainly related to impaired dentin mineralization. In dentin matrix, matrix extracellular phosphoglycoprotein (MEPE) may be protected from proteolysis by a specific interaction with PHEX (phosphate regulating gene with homologies to endopeptidases on the $X$ chromosome). The objective of our work was to determine whether PHEX impairment induces MEPE cleavage in dentin and the subsequent release of the $\mathrm{C}$-terminal acidic serine- and aspartate-rich motif (ASARM) peptide, which is known to inhibit mineralization. By Western blot analysis, we explored dentin extracts from seven hypophosphatemic patients with mutations of the PHEX gene. A proteomic approach combining immunoprecipitation, surface-enhanced laser desorption/ionization-time of flight-mass spectrometry and matrix-assisted laser desorption ionizationtime of flight analysis of the samples completed this exploration. This study shows a 4.1-kDa peptide containing the MEPE-derived ASARM peptide in hypophosphatemic samples. The presence of ASARM was less marked in patients treated with 1-hydroxylated vitamin D and phosphate during growth. More- over, recombinant ASARM implanted in a rat pulp injury model disturbed the formation of the reparative dentin bridge. These results suggest that abnormal MEPE cleavage occurs when PHEX activity is deficient in humans, the ASARM peptide may be involved in the mineralization defects and the PHEXMEPE interaction may be indirect, as ensuring a better phosphate and vitamin $D$ environment to the mineralizing dentin prevents MEPE cleavage. (Am J Pathol 2010, 177:803-812; DOI: 10.2353/ajpath.2010.091231)

Familial hypophosphatemic rickets, the most common cause of inherited rickets, is in most cases transmitted as an X-linked dominant trait and results from a mutation of the PHEX (phosphate regulating gene with homologies to endopeptidases on the $X$ chromosome) gene. ${ }^{1,2}$ PHEX encodes an endopeptidase, predominantly expressed in osteoblasts and odontoblasts. PHEX has been suggested to be involved in the cleavage of fibroblast growth factor-23, a phosphaturic hormone, therefore controlling its hyperphosphaturic effect. ${ }^{3,4}$ However, there is evidence that fibroblastic growth factor-23 is not a substrate for PHEX. ${ }^{5}$ X-linked hypophosphatemic rickets is associated with severe bony deformities, especially bowing of the legs, impaired growth, short stature, and severe dental troubles. The patients present spontaneous tooth abscesses that occur without any history of trauma or dental decay. Hypophosphatemic dentin was shown to display

Supported by the Institut Français pour la Recherche Odontologique, the Fondation de l'Avenir, and the University Paris Descartes funding (EA 2496) and by the National Institutes of Health (National Institute of Arthritis and Musculoskeletal and Skin Diseases grant R01-AR051598 to P.S.R.).

T.B. and C.G. contributed equally to this work.

Accepted for publication March 31, 2010.

Supplemental material for this article can be found on http://ajp. amjpathol.org.

Address reprint requests to Dr. Catherine Chaussain, Faculté de Chirurgie Dentaire-Université Paris Descartes, 1 rue Maurice Arnoux, 92120 Montrouge, France. E-mail: catherine.chaussain@parisdescartes.fr. 
important defects of mineralization that result in a high susceptibility of the teeth to necrosis. ${ }^{6,7}$

Matrix extracellular phosphoglycoprotein (MEPE) is an acidic phosphorylated protein of the bone and dentin extracellular matrix (ECM), first identified in patients with tumor-induced osteomalacia. ${ }^{8}$ It is expressed in bone by fully differentiated osteoblasts and is associated with an inhibition of bone formation and mineralization. ${ }^{9-11}$ It is also expressed by odontoblasts ${ }^{12}$ and pulp cells and was proposed to be used as a marker for odontoblast differentiation, being down-regulated when dental pulp stem cells reach confluence and initiate mineralization. ${ }^{13}$ MEPE belongs to the SIBLING family ${ }^{14,15}$ that shares many common features, such as containing a RGD sequence, a cell-attachment site, and an acidic serine- and aspartate-rich motif (ASARM). ${ }^{8}$ The ASARM of MEPE is located at its $C$ terminus and is proposed to regulate the mineralization process. Its deficiency results in accelerated osteoblast-mediated bone formation and mineralization without a change in phosphatemia. ${ }^{10,16}$ In the ECM, MEPE is protected from cleavage by a zinc-dependent protein-protein specific interaction with PHEX, via the ASARM. ${ }^{17}$ PHEX mutations result in absent or nonfunctional PHEX. Therefore, MEPE is exposed to a pathological cleavage within the matrix with the consequent release of protease-resistant ASARM peptides. ${ }^{17,18}$ These peptides may locally inhibit mineralization in the bone matrix and tubular phosphate reabsorption, because an accumulation of ASARM peptides has been observed in the renal proximal convoluted tubules of hyp mice, the murine homolog of the disease. ${ }^{19}$ In addition, a marked elevation of serum ASARM peptides was reported in human subjects with familial hypophosphatemic rickets. ${ }^{19}$

Because both PHEX and MEPE are expressed by odontoblasts, we hypothesized that the MEPE cleavage observed in the hypophosphatemic bone matrix also occurs in dentin. We previously demonstrated an accumulation of dentin sialoprotein, dentin matrix protein, bone sialoprotein, osteopontin, MEPE, and osteocalcin in the unmineralized interglobular spaces of hypophosphatemic dentin, with an abnormal expression of these proteins. ${ }^{20}$ In this work, we identified the presence of the ASARM peptide resulting from pathological MEPE cleavage in human hypophosphatemic dentin. The presence of this peptide may partially explain the impaired mineralization of the dentin associated with the familial X-linked hypophosphatemic rickets. In addition, the implantation of a phosphorylated recombinant peptide containing the MEPE-ASARM region in a rat pulp injury model further supports the inhibitory action of ASARM on mineralization.

\section{Materials and Methods}

\section{Sample Selection}

Teeth were collected from seven patients with X-linked hypophosphatemic rickets, all of whom were carrying an identified mutation on the PHEX gene. ${ }^{21}$ Table 1 gives the clinical and biological characteristic of the population studied. A total of 11 deciduous teeth were collected from the five younger patients (patients 1 to 5 ) after extraction due to spontaneous tooth necrosis (seven teeth) or to trauma (four teeth). Five permanent teeth were collected from the two older patients (patients 6 and 7) after extraction for orthodontic reasons. Sound teeth from seven healthy age-matched patients extracted for orthodontic reasons constituted the control group. Control teeth were from positions in the mouth similar to those for the related hypophosphatemic teeth.

Table 1. Clinical and Biological Characteristics of the Hypophosphatemic Patients at the Time of Tooth Extraction

\begin{tabular}{|c|c|c|c|c|c|c|c|}
\hline Patient & 1 & 2 & 3 & 4 & 5 & 6 & 7 \\
\hline Sex & $\mathrm{M}$ & M & $\mathrm{M}$ & $\mathrm{F}$ & M & M & $\mathrm{F}$ \\
\hline Age (years)* & 5 & 3 & 5 & 6 & 9 & 14.5 & 27 \\
\hline Treatment & + & + & + & + & + & + & + \\
\hline Age at onset (years) & 2 & 1.5 & 2.75 & 3.5 & 4.8 & 0.25 & 4.5 \\
\hline Duration (years) & 3 & 1.5 & 2.5 & 2.5 & 4.2 & $14^{+}$ & 22.5 \\
\hline Unalfa ( $\mu \mathrm{g} /$ day) & 1.5 & 1.2 & 2.5 & 1.5 & 1 & 1.5 & $1-3$ \\
\hline Phosphates (mg/kg/day) & 64 & 64 & 45 & 34 & 36 & 30 & 50 \\
\hline Compliance & Good & Good & Good & Good & Good & $\mathrm{Bad}$ & Good \\
\hline \multicolumn{8}{|l|}{ Signs of rickets } \\
\hline Leg bowing & + & ++ & ++ & + & 0 & +++ & 0 \\
\hline Height (SD) & -1 & -3 & -3 & -1 & -2 & 0 & -3 \\
\hline Serum phosphate $(\mathrm{mmol} / \mathrm{L})$ & 0.93 & 0.93 & 0.69 & 0.85 & 0.88 & 0.77 & 0.52 \\
\hline \multicolumn{8}{|l|}{ Dental status } \\
\hline DMFT or $\mathrm{dft}^{\ddagger}$ & 7 & 8 & 5 & 2 & 6 & 5 & 7 \\
\hline Collected tooth & $51,61,82$ & 51 & $51,61,74$ & 52,61 & 53,63 & $16,26,36,46$ & 38 \\
\hline Type $^{\S}$ & D & D & D & D & D & $\mathrm{P}$ & $\mathrm{P}$ \\
\hline Pulp status & Vital & Necrotic & Necrotic & Necrotic + vital & Necrotic & Endo $\mathrm{tt}^{\text {Tा }}$ & Vital \\
\hline
\end{tabular}

Heights are given in SD regarding reference curves for sex- and age-matched healthy children. All serum phosphate concentrations were below normal for the age.

* Age at the time of tooth collection

† The treatment of this child was irregularly followed from the beginning to 6 years, then stopped, and started again at 10 years.

‡ DMFT, decayed, missing, filled permanent tooth; dft, decayed, filled primary tooth.

$\S$ Type of collected tooth, deciduous (D) or permanent $(P)$.

II These teeth have been endodontically treated after decay and then extracted for orthodontic reasons.

$\mathrm{M}$, male; F, female. 
All teeth were obtained with the informed consent of parents and patients and with approval from our local ethics committee for humans. Immediately after collection, teeth were gently cleaned with tap water and kept at $-20^{\circ} \mathrm{C}$ before protein extraction.

\section{Recombinant ASARM Polypeptide}

Recombinant phosphorylated ASARM (P-ASARM) peptide including the MEPE-ASARM region $\left[\mathrm{NH}_{2}-\right.$ RDDSSESSDSGS $\left(\mathrm{PO}_{3} \mathrm{H}_{2}\right)$ SS $\left(\mathrm{PO}_{3} \mathrm{H}_{2}\right)$ ES $\left(\mathrm{PO}_{3} \mathrm{H}_{2}\right)$ DGD-OH] was obtained as reported previously. ${ }^{22}$

\section{Protein Extraction and Analysis of Dentin Proteins}

Hypophosphatemic and control teeth were prepared for dentin protein extraction. After enamel removal, standardized blocks of dentin $\left(1 \mathrm{~mm}^{3}\right)$ were prepared from the external half of the teeth with a saw equipped with a diamond disk under a continuous water spray. Blocks were immersed individually at $4^{\circ} \mathrm{C}$ in $0.5 \mathrm{M}$ acetic acid $(\mathrm{pH} 5)$ or $4.13 \%$ EDTA ( $\mathrm{pH} 7.2)$ for 7 days according to Boukpessi et al. ${ }^{23}$ The demineralized solutions were supplemented with 1/100 Proteinase Inhibitor Cocktail Set V, EDTA-Free (Calbiochem, La Jolla, CA).

\section{Western Blot Analysis}

EDTA-prepared dentin samples ( $1 \mu \mathrm{g} / \mathrm{lane}$ ) were diluted with Laemmli buffer and run on 12 or $8 \%$ SDS-polyacrylamide gel electrophoresis (PAGE) or on a Criterion 16.5\% acrylamide Tricine gel (Bio-Rad Laboratories, Hercules, CA). The proteins were transblotted on a nitrocellulose membrane (Trans-Blot Transfer Medium, Bio-Rad Laboratories) for time varying from 20 minutes to 2 hours. We used rabbit polyclonal antibodies against two regions of human MEPE (Table 2). ${ }^{8}$ After blocking, the membrane was incubated overnight at $4^{\circ} \mathrm{C}$ with either anti-mid-region MEPE (1/2000) or anti-MEPE-ASARM (1/2000) antibodies. The filter was incubated with a 1/1000 dilution of a horseradish peroxidase-linked anti-rabbit IgG for 2 hours at room temperature. The membrane was rinsed and developed by means of the Renaissance Western blot Chemiluminescence Reagent Plus Kit from NEN Life Science Products (Boston, MA). For each antibody, recombinant MEPE was used (30 ng/well) as a positive control. ${ }^{24}$ As a control for the protein loading, the antiASARM-labeled membrane was carefully washed and stripped with stripping buffer (Pierce Chemical, Rockford, IL), washed with transfer Tris-buffered saline, and processed as described previously with the anti-midregion MEPE antibody. The relative intensity of MEPEASARM/mid-region MEPE-specific bands was digitalized and compared using Image $\mathrm{J}$ (public domain image processing and analysis software developed at the $\mathrm{NIH}$ ). Values are presented as means \pm SD with at least four teeth per group. The significance of differences between means was assessed by Student's $t$-test analysis with $P<0.05$ considered significant.

\section{Immunoprecipitation Protocol}

Immunoprecipitation experiments were performed with acetic acid-prepared dentin samples from hypophosphatemic or control patients. Samples were diluted in a buffer containing $50 \mathrm{mmol} / \mathrm{L}$ potassium phosphate, 150 $\mathrm{mmol} / \mathrm{L} \mathrm{NaCl}, 0.1 \%$ SDS, $1 \%$ Triton $\mathrm{X}-100$, and $1 \%$ protease inhibitor mixture (Sigma-Aldrich, St. Louis, MO). Rabbit serum anti-ASARM $(25 \mu \mathrm{l})$ was diluted in $175 \mu$ l of buffer containing $15 \mu \mathrm{l}$ of protein $\mathrm{G}$ magnetic beads (Adamtech, Pessac, France) and $15 \mu$ of protein A magnetic beads (Ademtech) and gently mixed on a rotating wheel at $4^{\circ} \mathrm{C}$ for 2 hours. Antibody-coupled beads were then incubated for 2 hours at $4^{\circ} \mathrm{C}$ with $75 \mu$ l of dentin protein extract diluted in $125 \mu \mathrm{l}$ of buffer. Controls consisted of incubations of equivalent amounts of each lysate with nonimmune rabbit serum coupled to Sepharose beads in the same conditions. The beads were washed five times with the buffer for 5 minutes at $4^{\circ} \mathrm{C}$ under gentle agitation. Bound material was eluted in $20 \mu \mathrm{l}$ of a $50 \%$ acetonitrile, $0.1 \%$ trifluoroacetic acid solution; $10 \mu \mathrm{l}$ of eluate was loaded onto the normal-phase chromatography protein chip (NP20, Bio-Rad BioSystems, San Ramon, CA) and then analyzed by surface-enhanced laser desorption (SELDI)-mass spectrometry (MS).

\section{SELDI-Time of Flight-MS Analysis}

Fifty microliters of acetic acid-prepared sample was desalted using C18 columns (ZipTips, Millipore, Billerica, MA), according to the manufacturer's protocol. Ten microliters of desalted sample was applied onto an NP20 protein chip and air-dried, and then $2 \mu$ l of matrix solution was applied (sinapinic acid at $2 \mathrm{~g} / \mathrm{L}$ in 50\% [v/v] acetonitrile containing $0.5 \%[\mathrm{v} / \mathrm{v}]$ trifluoroacetic acid). Mass/ charge $(\mathrm{m} / \mathrm{z})$ spectra of peptides and proteins were generated in a SELDI-time of flight (TOF) system (PCS 4000,

Table 2. Sequence of Human MEPE (Reference NP_064588)

1-MRVFCVGLLL FSVTWAAPTF QPQTEKTKQS CVEEQRQEEK NKDNIGFHHL GKRINQELSS KENIVQERKK DLSLSEASEN KGSSKSQNYF TNRQRLNKEY SISNKENTHN GLRMSIYPKS TGNKGFEDGD DAISKLHDQE EYGAALIRNN MQHIMGPVTA IKLLGEENKE NTPRNVLNII PASMNYAKAH SKDKKKPORD SOAOKSPVKS KSTHRIOHNI DYLKHLSKVK KIPSDFEGSG YTDLQERGDN DISPFSGDGQ PFKDIPGKGE ATGPDLEGKD IQTGFAGPSE AESTHLDTKK PGYNEIPERE ENGGNTIGTR DETAKEADAV DVSLVEGSND IMGSTNFKEL PGREGNRVDA GSONAHOGKV EFHYPPAPSK EKRKEGSSDA AESTNYNEIP KNGKGSTRKG VDHSNRNQAT LNEKQRFPSK GKSQGLPIPS RGLDNEIKNE MDSFNGPSHE NIITHGRKYH YVPHRQNNST RNKGMPQGKG SWGRQPHSNR RFSSRRRDDS SESSDSGSSS ESDGD-525 
Bio-Rad BioSystems). Data were collected by averaging the results of a total of 550 laser shots with an intensity of $3.500 \mathrm{~nJ}$, a focus mass of $\mathrm{m} / \mathrm{z} 2.5 \mathrm{kDa}$, a high mass of $\mathrm{m} / \mathrm{z}$ $100 \mathrm{kDa}$, and an optimization range of $m / z 1$ to $10 \mathrm{kDa}$. Mass curacy was calibrated externally using the All-inOne peptide mass standard (Bio-Rad BioSystems), and SELDI-TOF-MS analysis was performed on the same day. ProteinChip Data Manager software was subsequently used to compare sample and for annotation of spectra.

\section{Nanochromatography-MS and Tandem Mass Spectrometry}

The peptides were separated with an UltiMate 3000 (Dionex, Bannockburn, IL) series nano-high-performance liquid chromatograph: column PepMap100 C18 (3 $\mu \mathrm{m}$, $15 \mathrm{~cm}$ length, $75 \mu \mathrm{m}$ i.d., $100 \AA$ A), $300 \mathrm{nl} / \mathrm{min}$ flow, gradient rising from $0 \%$ solvent $B$ (acetonitrile/solvent $A, 80: 20$, $\mathrm{v} / \mathrm{v}$ ) to $50 \%$ in 30 minutes (solvent $\mathrm{A}: \mathrm{H}_{2} \mathrm{O}, 2 \%$ acetonitrile and $0.1 \%$ trifluoroacetic acid). Chromeleon 6.8 software was used. Fractions were spotted on-line on a matrixassisted laser desorption ionization (MALDI) target using a Probot (Dionex) fraction collector. Fractions were mixed $1: 2(\mathrm{v} / \mathrm{v})$ with $2.5 \mathrm{mg} / \mathrm{ml}$ of $\alpha$-cyano-4-hydroxycinnamic acid (Laser Biolabs, Sophia-Antipolis, France) in 50\% acetonitrile (high-performance liquid chromatographygrade; VWR, West Chester, PA) and $0.1 \%$ trifluoroacetic acid (Pierce Chemical). Seventy-two fractions were collected and analyzed using a MALDI-TOF-TOF ABI 4800+ system (Applied Biosystems, Foster City, CA) equipped with a YAG 200-Hz laser (355 nm). Spectra acquisition and processing were performed using the 4000 Series Explorer software (version 3.5.1, Applied Biosystems). Generated tandem mass spectrometry (MS/MS) peaklists were submitted to an in-house Mascot (Matrix Science, Boston, MA) search engine (Database Search MSDB-2, precursor tolerance: 100 ppm, MS/MS tolerance: $0.3 \mathrm{Da})$.

\section{Implantation of Recombinant P-ASARM Peptide in a Rat Pulp Injury Model}

Affi-Gel agarose beads (Bio-Rad Laboratories) were soaked in a solution of P-ASARM peptide dissolved in PBS solution $(1 \mu \mathrm{g} / \mu \mathrm{l})$ for 2 hours, and dried overnight at $37^{\circ} \mathrm{C} .{ }^{25,26}$ The beads were implanted in the pulp of the first upper jaw molar of 12 rats ( 6 weeks, OFA/SD Charles River, Lyon, France). In brief, after gingival electrosurgery, half-moon-shaped class $\vee 0.5-\mathrm{mm}$ cavities were prepared on the mesial aspect of the first maxillary molars using a 0.2-mm diameter round bur (E0123, Dentsply Maillefer, Ballaigues, Switzerland). Pulp perforation was accomplished by pressure with the tip of a steel probe and 10 P-ASARM peptide-soaked beads were implanted in the injury. ${ }^{26}$ The protocol was approved by the Animal Care Committee of French Veterinary Services. Collateral molars were implanted with buffer-soaked beads as a control. Cavities were filled with glass ionomer cement (GC Fuji II, GC Corporation, Tokyo, Japan). Animals were anesthetized and sacrificed at 30 days after implantation by an intracardiac perfusion with paraformaldehyde/glutaraldehyde solution buffered with $0.1 \mathrm{M}$ sodium cacodylate at $\mathrm{pH} 7.2$ to 7.4 . Block sections including molars were dissected from the maxilla after a few minutes and immersed in the fixative solution for 24 hours at $4^{\circ} \mathrm{C}$. Tissue demineralization was performed in $4.13 \%$ EDTA for approximately 8 weeks. After tissue embedding in Paraplast, $8-\mu \mathrm{m}$-thick sections were cut and prepared for
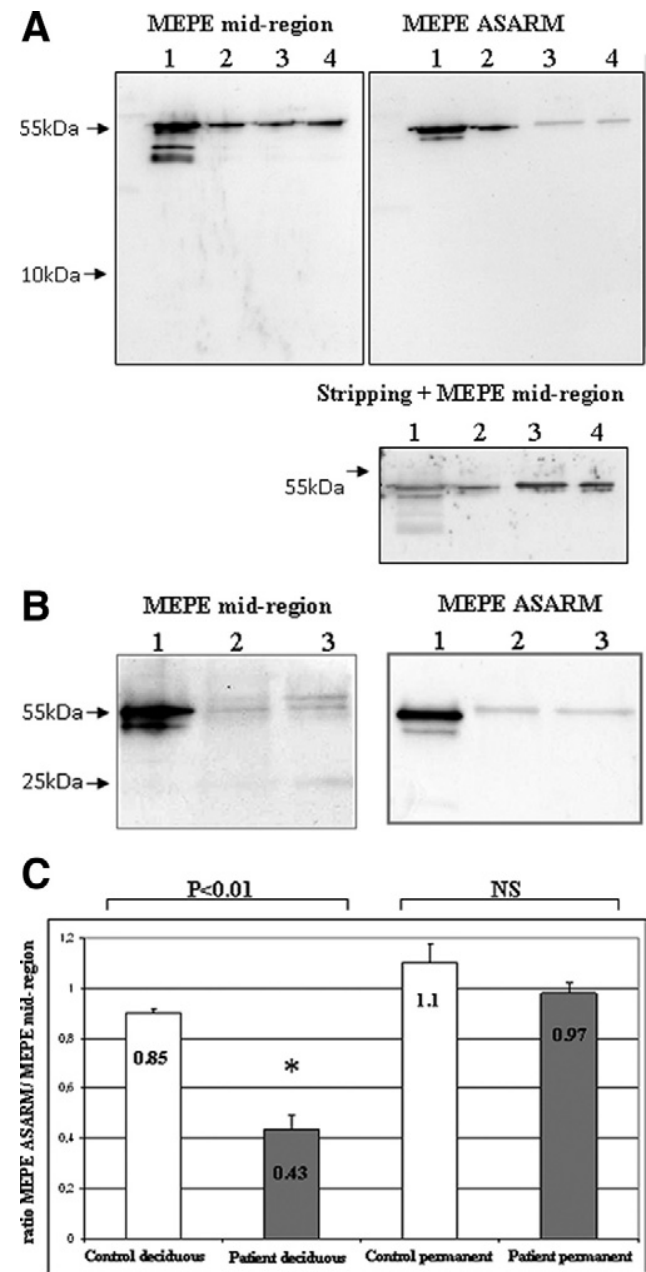

Figure 1. Western blot analysis of dentin extracts with MEPE antibodies after $12 \%$ SDS-PAGE. A: MEPE appears as a band at $55 \mathrm{kDa}$ in deciduous dentin extracts of similar intensity for control and hypophosphatemic samples with the MEPE mid-region antibody In contrast, a decrease in the band intensity is observed for hypophosphatemic samples with the ASARM antibody compared with control samples. Stripping and hybridization of this membrane with MEPE mid-region antibody confirms that the protein loading was correct. No difference is observed between vital and necrotic hypophosphatemic samples. Lane 1, recombinant MEPE (positive control); lane 2, control dentin; lane 3, vital hypophosphatemic dentin (patient 1); lane 4 , necrotic hypophosphatemic dentin (patient 2). B: MEPE appears as a double band at $55 \mathrm{kDa}$ in permanent dentin extracts with mid-region antibody and as a single band with ASARM antibody. A faint band is visualized in control and hypophosphatemic samples at approximately $25 \mathrm{kDa}$ with MEPE midregion antibody. No difference is observed between patient and control samples with both antibodies. Lane 1, recombinant MEPE; lane 2, control dentin; lane 3, hypophosphatemic dentin (patient 7). C: Quantification of Western blots using ImageJ software. Results are presented as ratios (mean \pm $\mathrm{SD}$ ) between the band of the MEPE-ASARM/MEPE mid-region intensities for both control and hypophosphatemic patients. Significant difference ( $\left.{ }^{*} P<0.01\right)$. Control deciduous teeth, $n=6$; hypophosphatemic deciduous teeth, $n=6$; control permanent teeth, $n=4$; hypophosphatemic permanent teeth, $n=4$. 


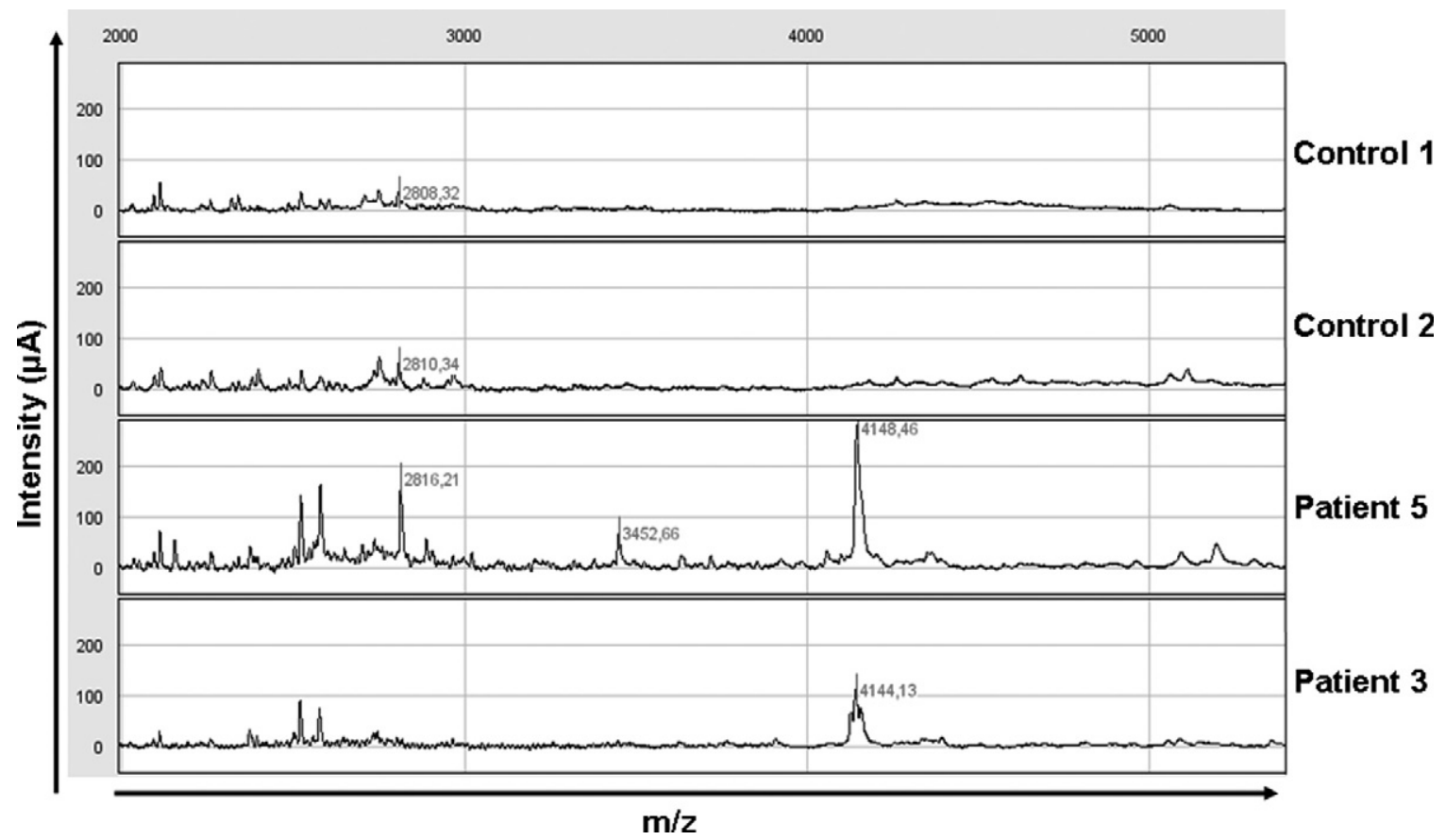

Figure 2. Representative mass spectra obtained by SELDI-TOF analysis of dentin extracts from control and hypophosphatemic patients (2000 to $5500 \mathrm{~m} / z$ ) Proteins/peptides were extracted from dentin by acetic acid, and the peptides were concentrated by hydrophobic C18 columns (ZipTips) before analysis by SELDI-TOF-MS using a nonselective normal phase surface (NP20). The masses of potential differential peaks between controls and patients are noted ( $m / z$ ).

staining with Masson's trichrome stain. The Masson's trichrome staining protocol is applied by immersion of rehydrated sample into hemalum and then successively into three different solutions (acid fuchsin/Ponceau solution, phosphomolybdic acid/orange G solution, and Light Green solution). The stain produces red erythrocytes, green collagen and dentin, light purple cytoplasm, and dark purple cell nuclei.

\section{Results}

\section{MEPE Is Cleaved in Hypophosphatemic Dentin When Mineralization Occurs before the Beginning of Phosphate and $1 \alpha$-Hydroxyvitamin $D_{3}$ Treatment}

Western blot analysis with the MEPE mid-region antibody after $12 \%$ SDS-PAGE showed a band at $55 \mathrm{kDa}$, which was of equivalent intensity for control and hypophosphatemic deciduous dentin extracts (patients 1 and 2) (Figure 1A). This band was also detected with the MEPEASARM antibody but with a markedly decreased intensity in the hypophosphatemic samples, whatever the pulp status (patient 1: vital tooth; patient 2: necrotic tooth). This decrease suggests a C-terminal cleavage of the protein that results from PHEX mutation and not from tooth necrosis. A thorough examination of the film did not allow the detection of a low molecular weight peptide that would correspond to the cleavage product enclosing the ASARM (Figure 1A, left panel). In contrast, permanent dentin extract from patient 7 showed similar intensity of the 55-kDa band with both antibodies, suggesting that
MEPE is not significantly cleaved in the permanent dentin of an adult hypophosphatemic patient adequately treated throughout growth (Figure 1B). Quantification of the band intensities confirmed that approximately $50 \%$ of MEPE underwent a C-terminal cleavage in deciduous hypophosphatemic samples, whereas no significant cleavage could be detected in permanent samples (Figure 1C).

\section{Direct Identification of the MEPE-Derived ASARM Peptide}

To better characterize the degradation profile of hypophosphatemic dentin, acetic acid-prepared samples were analyzed by SELDI-TOF-MS. Several peaks were observed in patients' extracts that were not present in control samples (Figure 2). Tandem mass spectrometry (MALDI-TOF-MS-MS) allows identification of peaks whose molecular masses are less than $3 \mathrm{kDa}$. Several of the peaks identified corresponded to peptides derived from type I collagen, particularly at 1.32 and $1.38 \mathrm{kDa}$, which corresponded to fragments of the $\alpha 2$ chain of type I collagen (Figure 3, A and B). None of the peaks corresponded to the MEPE-derived ASARM peptide, as recombinant phosphorylated and nonphosphorylated polypeptides corresponding to the minimal sequence of the MEPE-ASARM showed peaks at 2.1 and $1.9 \mathrm{kDa}$, respectively, when analyzed by SELDI-TOF-MS (Supplemental Figure 1, see http://ajp.amjpathol.org). Peaks immunoprecipitating with the MEPE-ASARM antibody were observed at $\mathrm{m} / \mathrm{z} 4.075$ and $4.141 \mathrm{kDa}$ in patients' dentin, but not in samples immunoprecipitated with nonrelevant 
A

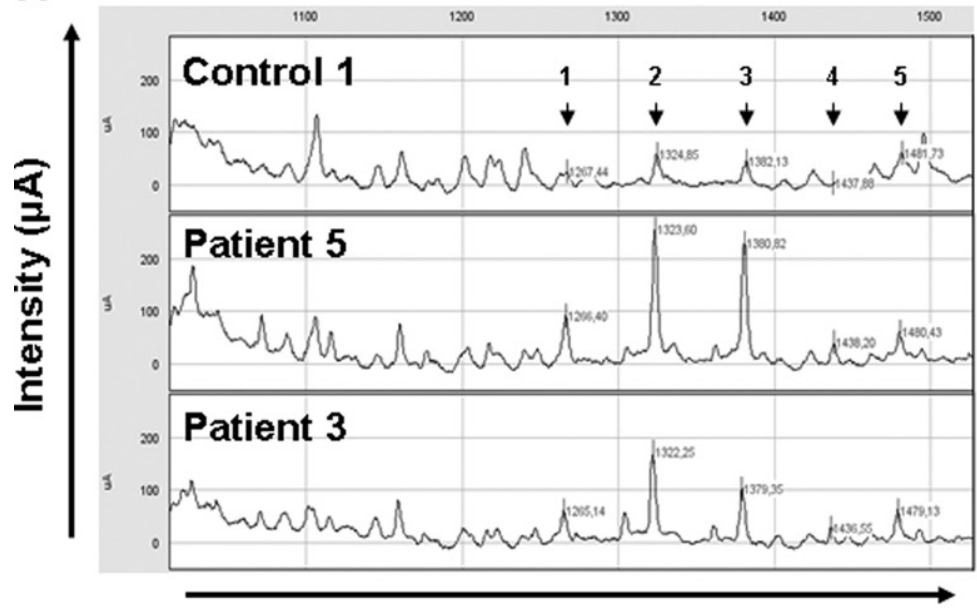

B

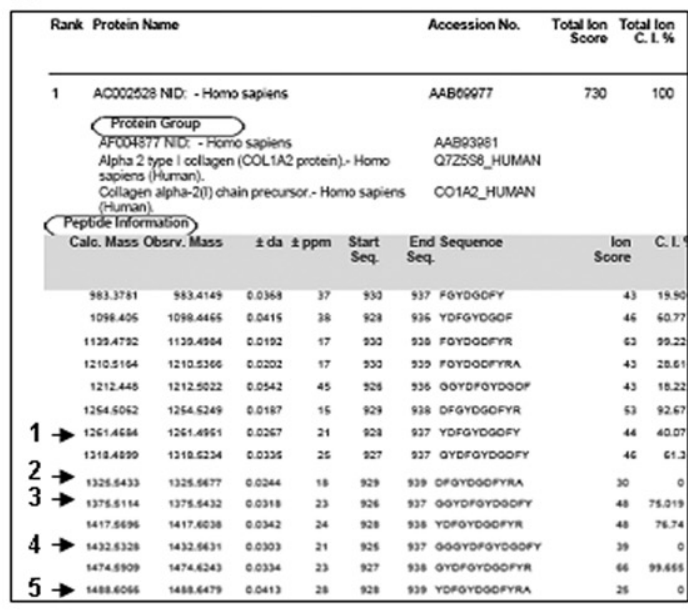

$\mathrm{m} / \mathrm{z}$

Figure 3. Representative degradation profiles for peptides between 1000 to $1550 \mathrm{~m} / z$. A: Representative mass spectra obtained by SELDI-TOF analysis comparing dentin extracts of controls and hypophosphatemic patients (1000 to $1550 \mathrm{~m} / \mathrm{z}$ ). The differential peaks that could be identified by MALDI-TOF-MS/MS are noted $(\mathrm{m} / \mathrm{z})$. B: List of peptides for which sequences could be obtained by MALDI-TOF-MS/MS after nano-high-performance liquid chromatography separation and corresponding to fragments of collagen (Q7Z5Q6 and CO1A2, Mascot). Arrows show the peptides that were found to be increased in dentin extracts from hypophosphatemic patients by SELDI-TOF-MS. Slight differences in $\mathrm{m} / z$ can be observed between SELDI and MALDI-MS because of different calibration of the spectrometers.

IgG or in control dentin samples (Figure 4). The 4.141 peak was further detected on SELDI-TOF mass spectra from crude extracts for all of the patients (Figure 5). However, the intensity of this peak in samples from patients 6 and 7 was 2 to 10 times lower compared with that of other patients.

Western blot analysis of dentin samples from patients 1,4 , and 6 with the MEPE-ASARM antibody, using a short transfer time (30 minutes) and appropriate gels for peptide identification, allowed the detection of a band at approximately 4 kDa (Figure 6), consistent with our proteomic analysis findings. In contrast, no band in the low molecular ranges was detected in the control subject and patient 7.

To confirm MEPE cleavage into a small MEPE-derived ASARM peptide in the hypophosphatemic dentin, we

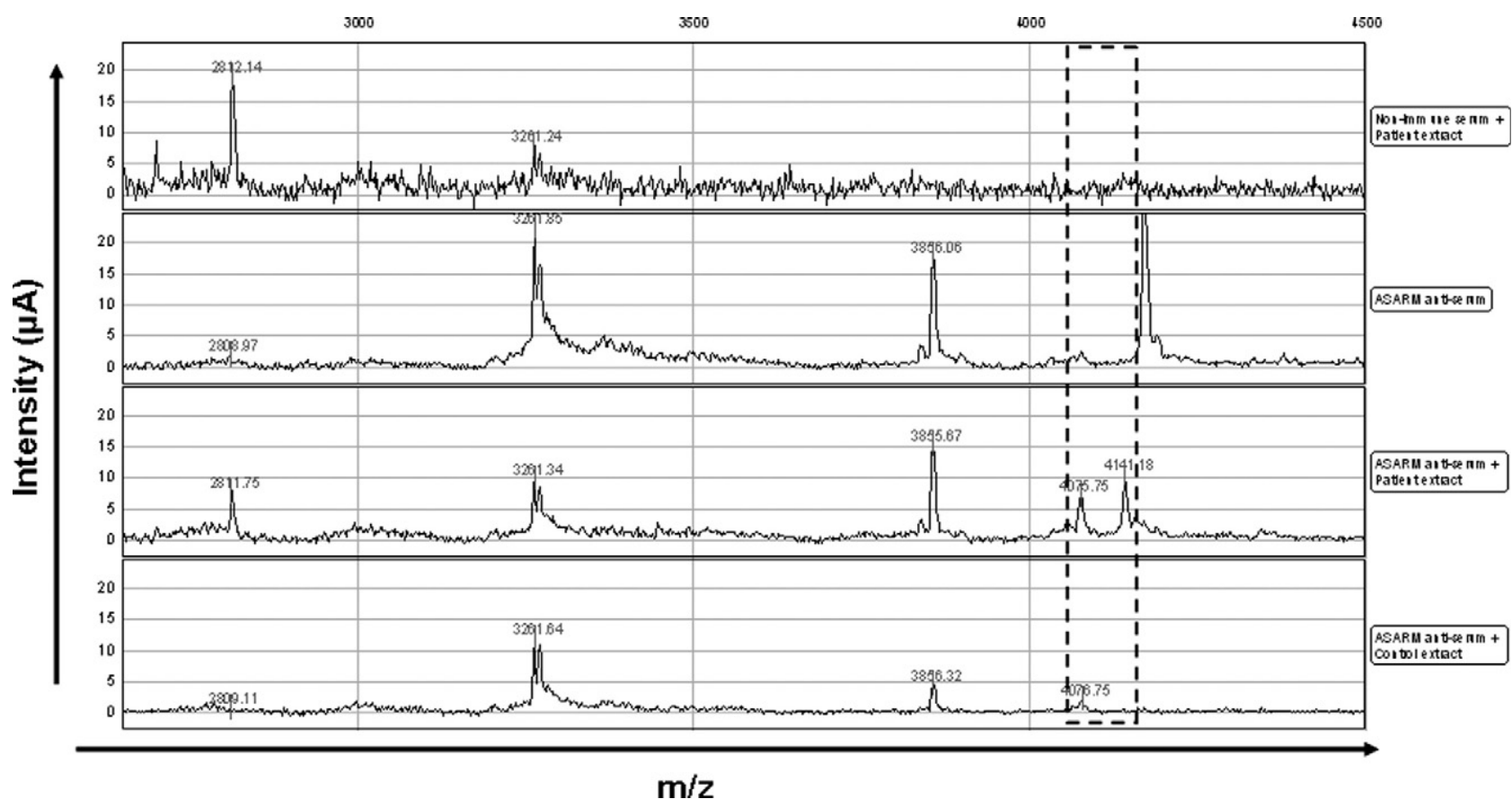

Figure 4. Direct identification of MEPE-derived ASARM peptide after immunoprecipitation. Mass spectra resulting from SELDI analysis after immunoprecipitation using rabbit anti-ASARM serum and nonimmune rabbit serum as a control. Nonspecific peaks contained either in anti-ASARM or nonimmune serum are excluded. Only $\mathrm{m} / z 4075$ and 4141 are (dashed box) considered as specific and present only in patient extract $(\mathrm{m} / \mathrm{z} 4141)$ and in a lower amount in control relative to patient extract $(m / z 4075)$. 


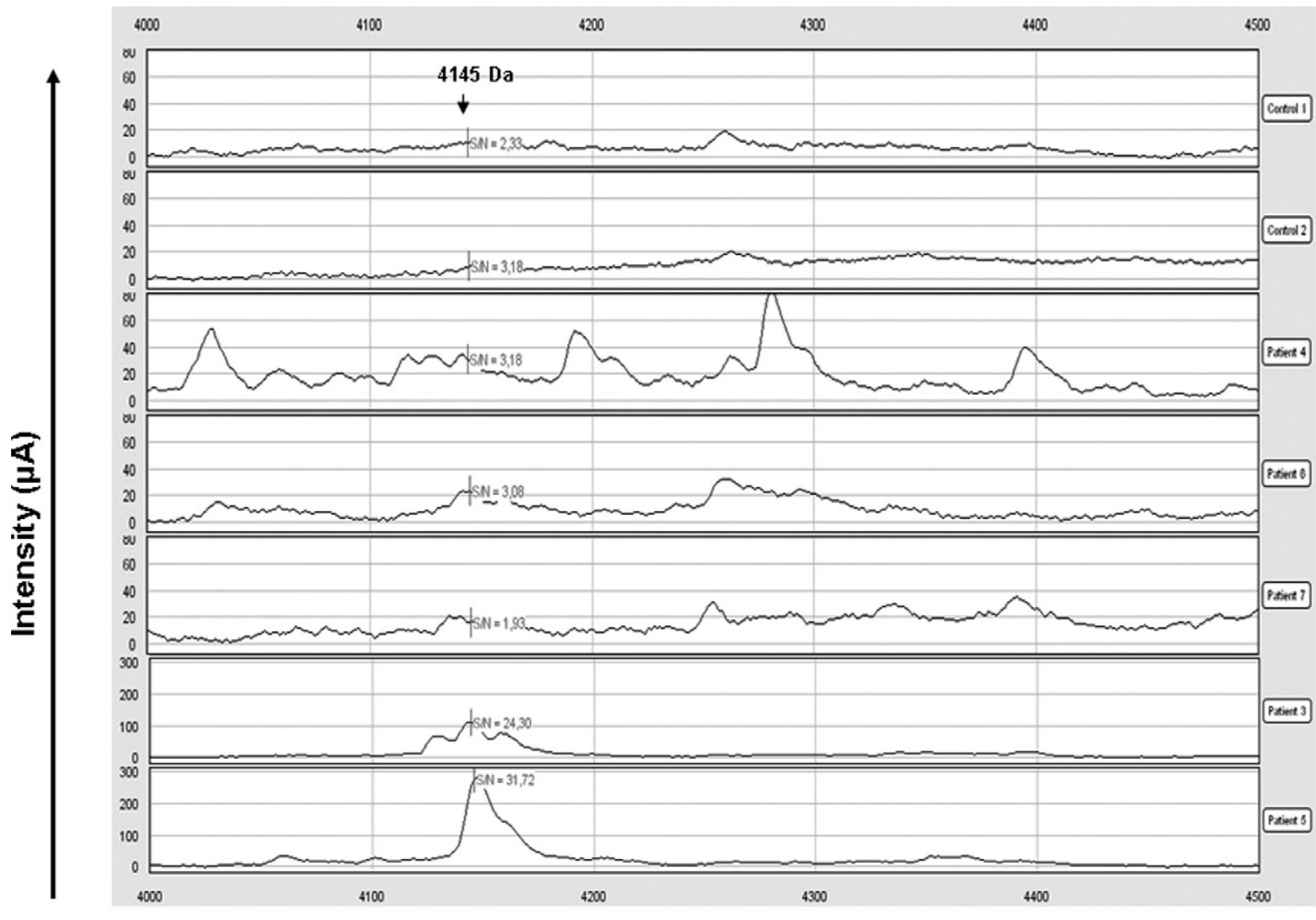

$\mathrm{m} / \mathrm{z}$

Figure 5. MEPE-derived ASARM peptide profiles by SELDI-TOF analysis. SELDI-TOF mass spectra after peptide enrichment by hydrophobic C18 columns (ZipTips) and analysis on nonselective normal phase surfaces (NP20). Dentin extracts from two control subjects and five patients were analyzed, focusing on $m / z$ 4144 (note the different scale of intensity for patients 3 and 5).

looked for the putative presence of a larger MEPE fragment lacking the 4.1-kDa MEPE-derived ASARM peptide. To do so, we examined by Western blot analysis a deciduous hypophosphatemic sample after 8\% SDS-PAGE, a gel with a looser polyacrylamide network more appropriate to separate proteins with a high molecular mass. In a hypophosphatemic sample (patient 4: vital tooth), two clear bands were detected with the MEPE mid-region antibody at 55 and approximately $50 \mathrm{kDa}$, respectively. In contrast, a single band was detected either in a control sample with MEPE mid-region antibody or in both samples with a MEPE-ASARM antibody (Figure 7, A and B). This finding is consistent with a C-terminal cleavage of the protein and the consequent release of a $4.1-\mathrm{kDa}$ cleavage product in the ECM.

\section{P-ASARM Peptide Disturbs Dentin Mineralization in an Animal Model of Pulp Injury}

To explore the potential of a MEPE-derived ASARM peptide to inhibit dentin mineralization, we implanted agarose beads soaked with the recombinant P-ASARM peptide in the injured pulp of young rats and followed the rate of healing in comparison with a control group treated with beads soaked in buffer only. After 1 month, a dentin bridge was observed in both control and ASARM-treated animals (Figure 8). In controls, the inflammation process was low, and the beads were embedded in the reparative dentin. In contrast, a severe inflammation process with a high cell infiltrate was observed in ASARM-implanted animals. Beads were surrounded by inflammatory cells and the dentin bridge associated with the beads displayed fibrous spaces that were not positive for green staining. These preliminary results demonstrate that a peptide comprising the MEPE-derived ASARM peptide impaired the reparative dentin bridge formation.

\section{Discussion}

In this work, we identified, for the first time, a MEPEderived ASARM peptide in a human mineralized hypophosphatemic tissue using proteomics-based methods. A marked elevation of serum ASARM peptides was previously demonstrated in human subjects and mice with X-linked hypophosphatemic rickets. ${ }^{19}$ Increased levels of ASARM peptides in bone and kidneys have also been reported for XLH mice. ${ }^{19,27,28}$ ASARM measure- 


\section{MEPE ASARM antibody}

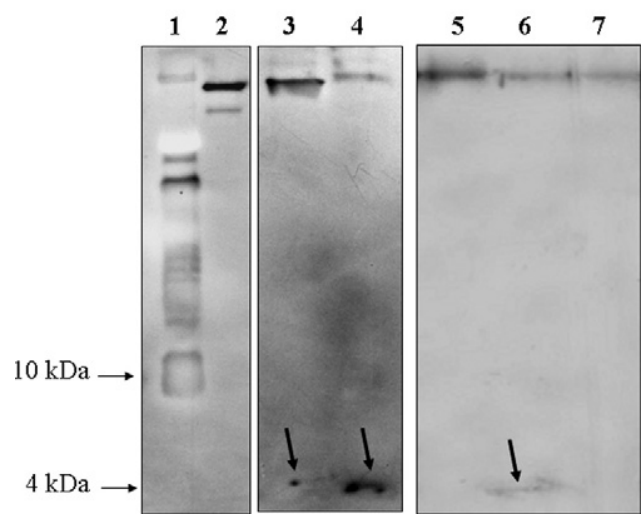

Figure 6. Direct identification of the ASARM peptide by Western blot using MEPE-ASARM antibody after electrophoresis on a $16.5 \%$ acrylamide Tricine gel. Lane 1, molecular weight marker; lane 2, recombinant MEPE; lane 3, hypophosphatemic dentin (patient 4); lane 4, hypophosphatemic dentin (patient 6); lane 5, control permanent dentin; lane 6, hypophosphatemic dentin (patient 1); lane 7, hypophosphatemic dentin (patient 7). After a 30-minute transfer, a faint band is observed at approximately $4 \mathrm{kDa}$ for patients 1,4 , and 6 as indicated by an arrow. In contrast, this band was not detected for patient 7 (well treated adult) and for control dentin.

ments for human bone and human or murine dentin matrix have not been reported to date. Recent studies highlighted the role of MEPE as a phosphatonin and as an inhibitor of mineralization related to its ASARM. ${ }^{29,30}$ In normal conditions, PHEX may regulate MEPE activity by sequestrating the protein through its C-terminal region. ${ }^{22}$ PHEX mutations result in the absence or in the loss of function of PHEX and expose unprotected MEPE to a pathological cleavage within the matrix. The resulting cleavage product, the ASARM peptide, constitutes a small, acidic and stable peptide, which is a potent inhibitor of mineralization. ${ }^{17,18,27}$ Therefore, the presence of this peptide in the dentin matrix that we demonstrated in this study may partially explain the mineralization defects observed in hypophosphatemic teeth.

This hypothesis is supported by preliminary in vivo data on the implantation of recombinant MEPE-derived $\mathrm{P}$ -
A

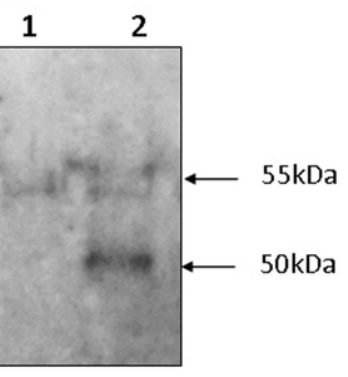

MEPE mid-region
B

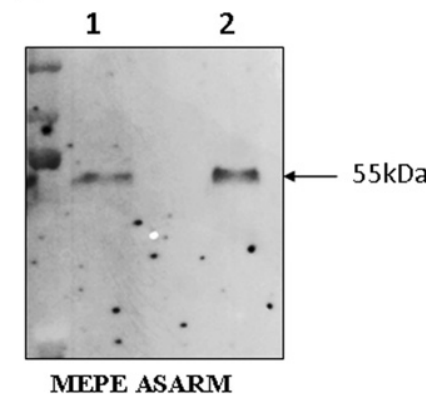

Figure 7. Western blot analysis of primary dentin extracts with MEPE antibodies after 8\% SDS-PAGE. A: MEPE mid-region. B: MEPE C-terminal (ASARM) region. Lane 1, control dentin; lane 2, vital hypophosphatemic dentin (patient 1). MEPE appears as a band at $55 \mathrm{kDa}$ in a control dentin extract with both antibodies ( $\mathbf{A}$ and $\mathbf{B}$ ). In a hypophosphatemic sample, two clear bands are detected with the MEPE mid-region antibody at 55 and approximately $50 \mathrm{kDa}(\mathbf{A})$, whereas a single $55-\mathrm{kDa}$ band is detected with the ASARM antibody (B).
ASARM peptide in a rat pulp injury model. In this model, a reparative dentin bridge was formed within a time lapse of 1 month to serve as a protective barrier to the dental pulp. ${ }^{25,26}$ We were able to report that P-ASARM peptide impaired the formation of the reparative dentin bridge classically observed in our model. The peptide induced abnormal purple-stained fibrous areas in the greenstained neo-formed dentin bridge that somehow evoked unmineralized interglobular spaces observed in hypophosphatemic human dentin. It has been recently shown that treatment of either MC3T3 osteoblasts or mouse-derived bone marrow stem cells with the same peptide caused a dose-dependent inhibition of mineralization. ${ }^{22,27}$ However, to the best of our knowledge, this is the first time that the disturbing effect of MEPE-derived ASARM peptide on the formation of a reparative structure is being reported in an in vivo model, suggesting its inhibitory effect on dentin mineralization. Other candidates as inhibitors of mineralization such as ASARMderived OPN have been proposed recently, and their possible involvement in association with ASARM-derived MEPE requires further investigations. ${ }^{31}$

Because teeth constitute an easily accessible tissue to collect compared with bone, we were able to collect teeth from seven hypophosphatemic patients with proven mutations of the PHEX gene. ${ }^{21}$ We previously reported an accumulation of degraded MEPE in interglobular spaces of hypophosphatemic dentin, independent of the pulp status (vital or necrotic). ${ }^{20}$ In addition, using a specific antibody against its C-terminal ASARM, we observed strong staining in interglobular spaces that may correspond to free ASARM peptides. ${ }^{32}$ In this work, we identified by Western blot analysis a 50-kDa cleaved fragment of MEPE and full-length MEPE in hypophosphatemic samples, supporting our previous findings that a part of MEPE was cleaved in hypophosphatemic dentin. ${ }^{20}$

In this study, proteomic analysis of dentin extracts confirms our previous findings that proteins were degraded in the dentin matrix ${ }^{20}$ as shown by the presence of several differential peptides in pathological conditions. However, among the various peaks observed in hypophosphatemic samples on the SELDI-TOF-MS profiles, we were not able to determine which one corresponded to the MEPE-derived ASARM peptide. MALDI-TOF analysis followed by sequencing (MS/MS) was possible for the peptides under $\mathrm{m} / \mathrm{z} 3 \mathrm{kDa}$. Indeed, it is technically very difficult to fragment peptides beyond this molecular mass using a collision chamber. Interestingly, among the peaks $<3 \mathrm{kDa}$, we were able to identify several peaks that corresponded to type I collagen. The degradation of this major component of the dentin ECM demonstrates a severe degradation of the dentin matrix that is not restricted to noncollagenous proteins as initially reported. ${ }^{20}$ This finding supports the fact that impaired dentin structure is responsible for the fast tooth necrosis in hypophosphatemic patients.

To identify the peak corresponding to MEPE-derived ASARM peptide among the large range of differential peaks detected in hypophosphatemic samples, we performed immunoprecipitation followed by SELDI-TOF-MS 
CONTROL

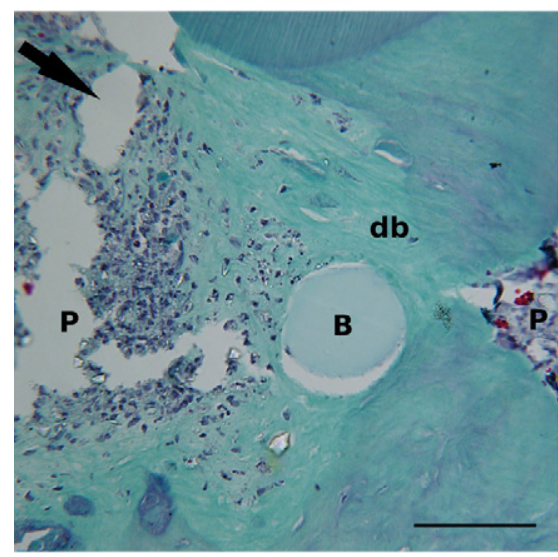

ASARM +

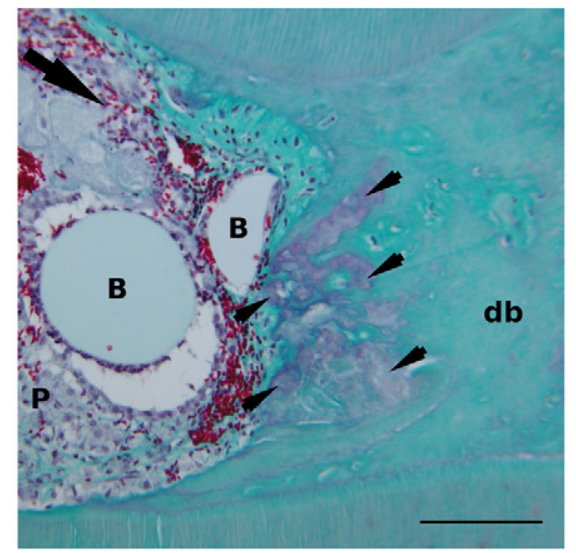

Figure 8. P-ASARM peptide disturbs pulp repai in an injured rat pulp model. Beads soaked with the peptide (right panel) or with buffer (left panel) were implanted in the injured pulp of young rats. Animals were sacrificed at day 30 and demineralized maxillary blocks were observed after Masson's trichrome staining. The arrowheads indicate purple-stained fibrous areas located in the green-stained reparative dentin bridge in ASARM animals. The arrow indicates the side of the pulp exposure. In the right panel, many red-stained erythrocytes are observed neighboring the beads. $\mathrm{db}$, dentin bridge $\mathrm{B}$, bead; P, pulp. Scale bars $=100 \mu \mathrm{m}$. analysis. At the same time, using an appropriate transfer time for blotting small peptides, we directly observed the ASARM peptide in dentin samples from several hypophosphatemic patients by Western blot analysis. It is interesting to note that both methods allowed determination of the molecular mass of the peptide derived from human dentin matrix at approximately $4 \mathrm{kDa}$, which differs from those of recombinant phosphorylated and nonphosphorylated MEPE-derived ASARM peptides. The residue sequence of both recombinants corresponds to the precise residue sequence of the MEPE-ASARM. ${ }^{22}$ In vitro data suggested that the enzyme responsible for MEPE cleavage in the matrix was cathepsin B and that the cleavage site was located before the ASARM within the protein sequence. ${ }^{24,33}$ According to SELDI-MS analysis, the sequence corresponding to the 4.1 peak we identified corresponds to GKGSWGRQPHSNR RFSSRRRDDSSESSDSGSSSESDGD (ProtParam tool from SwissProt) in the MEPE sequence, suggesting a potential cleavage site between residues $Q^{434}$ and $\mathrm{G}^{435}$. The identification of the enzyme responsible for this in vivo cleavage requires further investigation.

To differentiate the gene mutation effect from the effect of phosphate deficiency, we collected teeth from children whose dentin mineralization occurred mainly before the onset of the treatment as well as a permanent tooth from a young adult whose dentin had mineralized in a corrected phosphate and vitamin D environment. Dentin mineralization of deciduous teeth starts during intrauterine life. It goes on during early infancy before tooth eruption and, after eruption, until the beginning of root resorption because of the eruption of the underlying permanent tooth. The dentin mineralization process in the deciduous teeth that we analyzed in this study mainly took place before the beginning of the treatment and thus in a phosphate-deficient and a 1-hydroxylated-vitamin D-deficient environment. In contrast, the dentin mineralization of the permanent tooth occurred in a corrected phosphate and vitamin $D$ environment. We previously reported by immunochemical analysis and spectro electron microscopy observations that hypophosphatemic dentin mineralized in a corrected environment was comparable to sound dentin, with a normal location of the noncollagenous protein in the matrix. ${ }^{6,32}$ In the present study, we found lower amounts of MEPE-derived ASARM peptides in the two adult patients treated from early childhood and especially in the patient with better compliance to treatment (patient 7). Because MEPE is a phosphorylated protein member of the SIBLING family, ${ }^{14}$ we suggest that the phosphate deficiency resulting from the PHEX gene mutation impairs MEPE phosphorylation and decreases its resistance to cleavage. In addition, 1,25dihydroxyvitamin D deficiency may have aggravated the deleterious effect of phosphate deficiency as it controls phosphate transport and regulates MEPE expression. 9,33 Therefore, abnormal MEPE cleavage in the dentin of $X$-linked hypophosphatemic patients not only results from the lack of direct interaction between the MEPE and PHEX proteins but also from the phosphate- and vitamin D-deficient environment associated with PHEX impairment. Improving phosphate status and vitamin D conditions compensates for the PHEX gene dysfunction and limits MEPE cleavage; then normal mineralization can occur. Future research will allow development of an appropriate model to reproduce these important findings in vivo. However, these biological data are supported by our clinical data collected for 48 hypophosphatemic patients. ${ }^{7}$ Indeed, the patients who had received no treatment before puberty displayed severe dental status, whereas those who received phosphate supplements with $1 \alpha$-hydroxyvitamin $D_{3}$ from infancy had a normal dental status as regards reference ranges in healthy age-matched populations.

In conclusion, we report for the first time the presence of a MEPE-derived peptide that contains the ASARM in human hypophosphatemic dentin. We determined its molecular mass and propose a sequence for this peptide. The release of this peptide may partially explain the impaired dentin mineralization associated with the disease in teeth from hypophosphatemic patients with mutation of the PHEX gene. However, treatment during growth may limit the clinical consequences of this anomaly in the dentin of permanent teeth. This observation highlights the importance of improvement in the phosphate and vitamin $D$ environment, which compensate for the adverse effect of PHEX mutation on dentin mineralization. 


\section{Acknowledgments}

We thank the Plateforme Proteomique Structurale et Fonctionnelle from Institut Jacques Monod (University Paris Diderot, Paris, France) and IFR2, Institut Claude Bernard (Bichat, INSERM, Paris, France). We also thank Dr. Luc Camoin (Plateforme Protéomique de l'Institut Cochin, University Paris Descartes, Paris, France) for helpful discussion and Mrs. Dominique Septier (EA 2496, University Paris Descartes) for her assistance with histological analysis.

\section{References}

1. Rowe PS, Oudet CL, Francis F, Sinding C, Pannetier S, Econs MJ, Strom TM, Meitinger T, Garabedian M, David A, Macher MA, Questiaux E, Popowska E, Pronicka E, Read AP, Mokrzycki A, Glorieux FH, Drezner MK, Hanauer A, Lehrach H, Goulding JN, O'Riordan JL: Distribution of mutations in the PEX gene in families with X-linked hypophosphataemic rickets (HYP). Hum Mol Genet 1997, 6:539-549

2. Rowe PS: The role of the PHEX gene (PEX) in families with $X$-linked hypophosphataemic rickets. Curr Opin Nephrol Hypertens 1998, 7:367-376

3. Bowe AE, Finnegan R, Jan de Beur SM, Cho J, Levine MA, Kumar R, Schiavi SC: FGF-23 inhibits renal tubular phosphate transport and is a PHEX substrate. Biochem Biophys Res Commun 2001, 284 : 977-981

4. Campos M, Couture C, Hirata IY, Juliano MA, Loisel TP, Crine P, Juliano L, Boileau G, Carmona AK: Human recombinant endopeptidase PHEX has a strict $S 1^{\prime}$ specificity for acidic residues and cleaves peptides derived from fibroblast growth factor-23 and matrix extracellular phosphoglycoprotein. Biochem J 2003, 373:271-279

5. Liu S, Guo R, Simpson LG, Xiao ZS, Burnham CE, Quarles LD: Regulation of fibroblastic growth factor 23 expression but not degradation by PHEX. J Biol Chem 2003, 278:37419-37426

6. Chaussain-Miller C, Sinding C, Septier D, Wolikow M, Goldberg M, Garabedian M: Dentin structure in familial hypophosphatemic rickets: benefits of vitamin D and phosphate treatment. Oral Dis 2007 , 13:482-489

7. Chaussain-Miller C, Sinding C, Wolikow M, Lasfargues JJ, Godeau G, Garabedian M: Dental abnormalities in patients with familial hypophosphatemic vitamin D-resistant rickets: prevention by early treatment with 1-hydroxyvitamin D. J Pediatr 2003, 142:324-331

8. Rowe PS, de Zoysa PA, Dong R, Wang HR, White KE, Econs MJ, Oudet CL: MEPE, a new gene expressed in bone marrow and tumors causing osteomalacia. Genomics 2000, 67:54-68

9. Argiro L, Desbarats M, Glorieux FH, Ecarot B: Mepe, the gene encoding a tumor-secreted protein in oncogenic hypophosphatemic osteomalacia, is expressed in bone. Genomics 2001, 74:342-351

10. Gowen LC, Petersen DN, Mansolf AL, Qi H, Stock JL, Tkalcevic GT, Simmons HA, Crawford DT, Chidsey-Frink KL, Ke HZ, McNeish JD, Brown TA: Targeted disruption of the osteoblast/osteocyte factor 45 gene (OF45) results in increased bone formation and bone mass. J Biol Chem 2003, 278:1998-2007

11. Quarles LD: FGF23, PHEX, and MEPE regulation of phosphate homeostasis and skeletal mineralization, Am J Physiol Endocrinol Metab 2003, 285:E1-E9

12. MacDougall M, Simmons D, Gu TT, Dong J: MEPE/OF45, a new dentin/bone matrix protein and candidate gene for dentin diseases mapping to chromosome 4q21. Connect Tissue Res 2002, 43: 320-330

13. Liu H, Li W, Shi S, Habelitz S, Gao C, Denbesten P: MEPE is downregulated as dental pulp stem cells differentiate. Arch Oral Biol 2005 , 50:923-928
14. Fisher LW, Fedarko NS: Six genes expressed in bones and teeth encode the current members of the SIBLING family of proteins. Connect Tissue Res 2003, 44(Suppl 1):33-40

15. Qin C, Baba O, Butler WT: Post-translational modifications of sibling proteins and their roles in osteogenesis and dentinogenesis. Crit Rev Oral Biol Med 2004, 15:126-136

16. Liu S, Brown TA, Zhou J, Xiao ZS, Awad H, Guilak F, Quarles LD: Role of matrix extracellular phosphoglycoprotein in the pathogenesis of X-linked hypophosphatemia. J Am Soc Nephrol 2005, 16:1645-1653

17. Rowe PS, Garrett IR, Schwarz PM, Carnes DL, Lafer EM, Mundy GR, Gutierrez GE: Surface plasmon resonance (SPR) confirms that MEPE binds to PHEX via the MEPE-ASARM motif: a model for impaired mineralization in X-linked rickets (HYP). Bone 2005, 36:33-46

18. Rowe PS: The wrickkened pathways of FGF23, MEPE and PHEX. Crit Rev Oral Biol Med 2004, 15:264-281

19. Bresler D, Bruder J, Mohnike K, Fraser WD, Rowe PS: Serum MEPEASARM-peptides are elevated in X-linked rickets (HYP): implications for phosphaturia and rickets. J Endocrinol 2004, 183:R1-R9

20. Boukpessi T, Septier D, Bagga S, Garabedian M, Goldberg M Chaussain-Miller C: Dentin alteration of deciduous teeth in human hypophosphatemic rickets. Calcif Tissue Int 2006, 79:294-300

21. Gaucher C, Walrant-Debray O, Nguyen TM, Esterle L, Garabedian M, Jehan F: PHEX analysis in 118 pedigrees reveals new genetic clues in hypophosphatemic rickets. Hum Genet 2009, 125:401-411

22. Martin A, David V, Laurence JS, Schwarz PM, Lafer EM, Hedge AM, Rowe PS: Degradation of MEPE, DMP1, and release of SIBLING ASARM-peptides (minhibins): ASARM-peptide(s) are directly responsible for defective mineralization in HYP. Endocrinology 2008, 149:1757-1772

23. Boukpessi T, Menashi S, Camoin L, Tencate JM, Goldberg M, Chaussain-Miller C: The effect of stromelysin-1 (MMP-3) on non-collagenous extracellular matrix proteins of demineralized dentin and the adhesive properties of restorative resins. Biomaterials 2008, 29:4367-4373

24. Guo R, Rowe PS, Liu S, Simpson LG, Xiao ZS, Quarles LD: Inhibition of MEPE cleavage by Phex. Biochem Biophys Res Commun 2002, 297:38-45

25. Chaussain C, Eapen AS, Huet E, Floris C, Ravindran S, Hao J, Menashi S, George A: MMP2-cleavage of DMP1 generates a bioactive peptide promoting differentiation of dental pulp stem/progenitor cell. Eur Cell Mater 2009, 18:84-95

26. Six N, Septier D, Chaussain-Miller C, Blacher R, DenBesten P, Goldberg M: Dentonin, a MEPE fragment, initiates pulp-healing response to injury. J Dent Res 2007, 86:780-785

27. Addison WN, Nakano Y, Loisel T, Crine P, McKee MD: MEPE-ASARM peptides control extracellular matrix mineralization by binding to hydroxyapatite: an inhibition regulated by PHEX cleavage of ASARM. J Bone Miner Res 2008, 23:1638-1649

28. Rowe PS, Matsumoto N, Jo OD, Shih RN, Oconnor J, Roudier MP Bain S, Liu S, Harrison J, Yanagawa N: Correction of the mineralization defect in hyp mice treated with protease inhibitors CA074 and pepstatin. Bone 2006, 39:773-786

29. David V, Martin A, Hedge AM, Rowe PS: Matrix extracellular phosphoglycoprotein (MEPE) is a new bone renal hormone and vascularization modulator. Endocrinology 2009, 150:4012-4023

30. Marks J, Churchill LJ, Debnam ES, Unwin RJ: Matrix extracellular phosphoglycoprotein inhibits phosphate transport. J Am Soc Nephrol 2008, 19:2313-2320

31. Addison W, Masica D, Gray J, McKee MD: Phosphorylation-dependent inhibition of mineralization by osteopontin ASARM peptides is regulated by PHEX cleavage. J Bone Miner Res 2009, 25:695-705

32. Gaucher C, Boukpessi T, Septier D, Jehan F, Rowe PS, Garabedian M, Goldberg M, Chaussain-Miller C: Dentin noncollagenous matrix proteins in familial hypophosphatemic rickets. Cells Tissues Organs 2009, 189:219-223

33. Rowe PS, Kumagai Y, Gutierrez G, Garrett IR, Blacher R, Rosen D, Cundy J, Navvab S, Chen D, Drezner MK, Quarles LD, Mundy GR: MEPE has the properties of an osteoblastic phosphatonin and minhibin. Bone 2004, 34:303-319 